\title{
Realismo neoclásico y la política exterior de Estados Unidos en Oriente Medio*
}

\section{Neoclassical Realism and the US Foreign Policy in the Middle East}

Fabio Sánchez a

Universidad Sergio Arboleda, Colombia

fabio.sanchez@usa.edu.co

ORCID: http://orcid.org/0000-0002-0042-9830
DOI: https://doi.org/10.11144/Javeriana.papo23-2.rnpe Redalyc: http://www.redalyc.org/articulo.oa?id=77757839007

Fecha de recepción: 20 Junio 2017

Fecha de aprobación: 25 Enero 2018

Fecha de publicación: 18 Diciembre 2018

\section{Resumen:}

Este artículo analiza, según el realismo neoclásico, los factores sistémicos y domésticos que influyeron en algunos hitos de la política exterior de Estados Unidos hacia Oriente Medio, desde el siglo XVIII hasta el final de la Guerra Fría. En la primera sección estudiamos las interacciones tempranas durante el siglo XVIII. Luego, observamos la primera mitad del siglo XX hasta el fin de la Guerra Fría, hecho que genera cambios fuertes en el pensamiento de la élite política estadounidense hacia la región. Posteriormente, nos centramos en la reacción de Saddam Hussein que ocasiona la guerra del Golfo en 1990. Finalmente, algunas conclusiones.

Palabras clave: Oriente Medio, Guerra Fría, Estados Unidos, política exterior, realismo neoclásico, Irak, geoestrategia.

\begin{abstract}
:
This article examines, under the neoclassical realism, those systemic and domestic factors influencing some of the milestones in the USA foreign policy regarding the Middle East by the end of the Cold War. In the first part herein, we study the early interactions during the 18th century. Next, we observe the events from the 20th century first half to the end of the Cold War, when strong changes took place in the political elite thinking of the United States regarding the Middle East. Finally, we focus on Saddam Hussein's reaction that eventually led to the Gulf War in 1990, and then we draw some conclusions.
\end{abstract}

Keywords: Middle East, Cold War, United States of America, foreign policy, neoclassical realism, Iraq, geo-strategy.

Oriente Medio representa una obsesión estratégica para los intereses de Estados Unidos. La literatura sobre las relaciones internacionales de los actores de la región (Fawcett, 2005; Halliday, 2005) y su política exterior es amplia (Hinnebusch y Ehteshami, 2002). También existen trabajos que analizan el papel que ha cumplido históricamente Estados Unidos en la zona, donde enfatiza su interés por los recursos energéticos (Bichler y Nitzan, 2004; Nitzan y Bichler, 2002, 2006), las relaciones con Egipto, Irán, Irak y Arabia Saudita (Heydemann, 2000; Howard, 1974; T. Ismael, 1986), y también la compleja relación con Israel (Mearsheimer y Walt, 2007a , 2007b). Trabajos más recientes han analizado las difi cultades que enfrenta Washington en la región luego de la guerra de Irak en el 2003, una intervención ilegal que representa el último gran fiasco de las aventuras militares estadounidenses (Dunn, 2003; Herring y Rangwala, 2005; Klarevas, Gelpi y Reifler, 2006; Layne, 2009; Le Billon, 2005). Este trabajo busca a través del realismo neoclásico (RNC) explicar factores sistémicos y domésticos que delinearon el accionar de Estados Unidos en la región, antecedentes que son fundamentales para comprender el crítico panorama de una zona marcada por los conflictos, el autoritarismo, el fundamentalismo y la intervención de las potencias occidentales.

El artículo continúa de la siguiente manera: en la primera parte se exponen las virtudes del RNC como marco analítico; posteriormente, se presentan los inicios de la relación entre Estados Unidos y Oriente Medio 
(siglo XVIII - 1945). Luego, se estudia el papel de Washington durante la Guerra Fría y la reacción de Saddam Hussein que llevó a la guerra del Golfo de 1991. Finalmente, algunas conclusiones.

\section{Realismo neoclásico para el estudio de la política exterior}

El realismo neoclásico (RNC) resulta útil para analizar los factores sistémicos y domésticos que afectan el comportamiento de los Estados en el sistema internacional (Lobell, Ripsman y Taliaferro, 2009). Esta vertiente va más allá del realismo clásico (Morgenthau, 1948) y del estructural (Waltz, 1979) y ha sido utilizada en diferentes casos para explicar la importancia de diversos factores domésticos - persuasivos y poderosos- que moldean la política exterior (Brawley, 2009; Fordham, 2009; Lobell, 2009): la ideología para extraer recursos (Schweller, 1998, 2009); el interés nacional por intervenir militarmente (Dueck, 2004, 2009) y el papel de las fuerzas sociales en la orientación de la acción exterior de los Estados (Ripsman, 2009; Ripsman y Levy, 2008; Sterling-Folker, 2009). Dichos aspectos son útiles a la hora de analizar el papel de Estados Unidos en Oriente Medio. Tal y como veremos, la ideología, el interés por los recursos y las alianzas, antes y durante la Guerra Fría, fueron determinantes en el papel que Washington cumplió en la región. Asimismo, el RNC permite identificar la variación de los intereses de un actor a través del tiempo (Schweller, 1998, 2004, 2009).

Una característica adicional del RNC para este trabajo es la visión multidimensional que ofrece del Estado. Lo concibe como un espacio de acuerdos o desencuentros entre el Ejecutivo, el Legislativo y otras fuerzas como los partidos políticos, los grupos económicos y la opinión pública (Lobell et al., 2009, p. 26). Tal y como veremos, la postura de Estados Unidos hacia Oriente Medio ha variado, debido a los cambios de presidentes y asesores, intereses y las propias presiones sistémicas y domésticas, en las que el petróleo, Israel y el enfrentamiento con la Unión Soviética durante la Guerra Fría delinearon un intervencionismo que aún marca la lógica política de Oriente Medio.

\section{Auge y crisis de la relación: del siglo XVIII a 1945}

No es posible entender el contexto político de Oriente Medio sin analizar el papel que Estados Unidos ha desempeñado en la región. Su rol político, militar y económico es particular e incluso paradójico. Las primeras relaciones fueron de tipo comercial, educativo y misionero. Los intercambios comerciales iniciales datan de $1767^{[1]}$, y entre 1801 y 1805 se presentaron encuentros en las costas de Trípoli, entre marines y piratas que habían robado embarcaciones mercantes estadounidenses. Tal como veremos a continuación, una mezcla de factores domésticos y sistémicos determinará la acción de Estados Unidos en la región.

Años después, en 1820, una misión protestante estableció un importante centro en Beirut, que a pesar del poco éxito que tuvo en conseguir conversiones religiosas, fue un modelo a seguir con su sistema educativo, lo cual facilitó la posterior fundación del Syrian Protestant College, el cual más tarde se convertiría en The American University of Beirut. Es de anotar la observación de Tareq Ismael (1986) sobre el aprecio que generaba hacia Estados Unidos este tipo de actividades educativas en la población local hasta antes de 1945.

Tiempo atrás, durante los siglos XVIII y XIX, Estados Unidos firmó varios tratados con países de la región. Reconoció la independencia de Marruecos en 1792, y firmó sucesivamente en 1830, 1862 y 1871 una serie de pactos para incentivar el comercio y garantizar el tránsito a través de los estrechos en tiempo de paz con el Imperio otomano. De la misma manera, ratificó acuerdos comerciales y de amistad con Omán en 1835 y con Persia en 1857. Y como dato más particular, los armadores de barcos estadounidenses ayudaron a reconstruir la armada otomana, destruida por los europeos durante la batalla de Navarino en 1827. Como se puede ver, estos acuerdos diferían de los que estos países habían alcanzado con las potencias europeas en la misma época, 
ya que Estados Unidos no era hasta ese momento un país con deseos de explotar sus recursos, y aunque claramente no lo eran, tampoco los trataba como potencias inferiores.

Posteriormente, el prestigio de Estados Unidos en la región aumentó con la Declaración de Principios del presidente Woodrow Wilson — factor doméstico—, quien buscaba un orden mundial más justo luego de la Primera Guerra Mundial —factor sistémico-, momento en el que Estados Unidos se fortaleció por la devastación de Europa. Lo anterior, favoreció la libre autodeterminación de un sistema post-otomano de países, que ansiaba manejar su propio destino político. Una visión claramente opuesta a la tendencia anglofrancesa $^{[2]}$ de extender sus dominios coloniales. Asimismo, Wilson envió a las comisiones King-Crane y Harbord hacia Siria y Armenia, respectivamente, como un esfuerzo por determinar las aspiraciones de sus habitantes luego de la guerra ${ }^{[3]}$. A este respecto, Tareq Ismael sostiene: "Ninguna de estas comisiones trató de influenciar el curso de los hechos, pues demostraron una simpatía por el estado de emergencia de los movimientos nacionales de Oriente Medio" (1986). Es destacable que la Comisión King-Crane enfatizara en la decisión del Congreso Nacional Sirio de 1919 de establecer un mandato americano en la región, si fuera extremadamente necesaria alguna clase de liga de naciones que tomara el control durante algún tiempo ${ }^{[4]}$.

Hoy puede resultar curioso, pero días antes de la Segunda Guerra Mundial, a nivel sistémico, Estados Unidos era el país en el que más se confiaba en Oriente Medio; su llegada al norte de África durante la Segunda Guerra Mundial fue vista de manera positiva. Tenía la reputación de jugar limpio y respetar a las otras naciones, además de un historial filantrópico que lo diferenciaba bastante de los países europeos. Y lo más importante era la percepción general de la población: consideraban que Estados Unidos era un país antiimperialista, tanto en su filosofía como en sus decisiones políticas. Desafortunadamente, esta visión cambiaría radicalmente luego del final de la Segunda Guerra Mundial en 1945.

A partir de ese momento, Estados Unidos inició una actuación diferente e intensa en la región, con el propósito de asegurar recursos energéticos. Por otra parte, brindó protección y armas a Israel, un aliado vital que le ayudaría en su competición internacional con la Unión Soviética, pero que al mismo tiempo le alejaría de la región

\section{Guerra Fría: contención y petróleo}

Durante la Guerra Fría la disputa ideológica, política y militar entre Estados Unidos y la Unión Soviética se centró en áreas geográficas estratégicas (Gaddis, 1982, 2007; “X” Kennan, 1947). Esto consolidó las zonas de influencia y la política de contención que desarrolló Washington en dicho periodo. Oriente Medio representaba una zona vital por varios aspectos: (i) su ubicación en medio de tres continentes (Europa, Asia y África), (ii) sus vías marítimas y puertos cruciales, y (iii) su proximidad a la Unión Soviética y el Mediterráneo. Para algunos autores, esta última circunstancia moldeó el carácter político de los principales intereses estadounidenses en la región.

Asimismo, junto con el proceso de descolonización y la salida de los aliados europeos de la región, la Unión Soviética amplió sus objetivos en la región e inició una postura agresiva luego de la derrota alemana en 1945 [5] . Esto ocasionó una activa reacción por parte de Washington, apoyando a las monarquías y atacando a los nacionalistas, considerados piezas de la estrategia de Moscú (Bosemberg, 2003, p. 11). A partir de aquel momento, la protección de intereses vitales en la zona sería parte integral de su política exterior hacia Oriente Medio, la cual contó con un aliado excepcional que le hizo el trabajo de contención: Israel. Un nuevo y "moderno" Estado que se ganó la confianza de las diferentes administraciones de Washington por sus victorias contundentes en los siguientes conflictos: (i) primera guerra Árabe-Israelí (1948-1949), (ii) Crisis del canal de Suez (1956), (iii) guerra de los 6 Días (1967) y (iv) guerra del Yom Kipur (1973) ${ }^{[6]}$.

Las demostraciones de poder de la Unión Soviética en la región ocasionaron que Estados Unidos identificara a Oriente Medio como un "campo de batalla" internacional. Estaba en juego la zona con las 
reservas más grandes de petróleo en el mundo, así como también puertos y vías marítimas que debía proteger de la otra "gran potencia" autosuficiente en hidrocarburos. Asimismo, el crudo proveniente de la región llenaba el espacio vital entre producción y demanda en el propio mercado de Estados Unidos ${ }^{[7]}$.

Por lo tanto, luego del embargo posterior a la guerra de 1973, Washington consideró el petróleo de Oriente Medio como uno de sus más importantes intereses nacionales, con el ánimo de consolidar un poder de veto (Chomsky, 2004) y fortalecer su influencia a nivel global (Aranda y José, 2005). A tal punto que el presidente Jimmy Carter manifestó que esté debería ser uno de los principios básicos de la política exterior estadounidense y, además, que el país debería ir a la guerra en caso de que cualquier enemigo quisiera tomar el control de los recursos de la región.

Para lograr este propósito, Estados Unidos construyó un sistema de relaciones sólidas con los países productores de petróleo en la región. Un trato de doble vía que implicaba la protección de los "débiles" países del golfo Pérsico, a cambio del flujo ininterrumpido de crudo hacia Occidente. Ni siquiera la revolución iraní o el alza en los precios fueron obstáculos. Tareq Ismael lo resume así:

En ocasiones se han presentado conflictos sobre los precios, pero esto se ha resuelto por el hecho de que los productores han invertido en las economías Occidentales, y porque han acordado mantener una alta producción para estabilizar los costos del petróleo. El cambio de gobierno en Irán fue una pérdida, pero fue adecuadamente compensado por la continuidad de la estrecha relación con los países árabes del Golfo, especialmente Arabia Saudita. (1986, p. 137)

En el mismo orden, Washington siempre buscó mantener un “consenso estratégico” con algunos países de Oriente Medio. Elaboró acuerdos políticos muy cercanos a sistemas de alianzas que tenían el propósito de contener a la Unión Soviética, bajo la premisa de que varios Estados de la región compartían los mismos ideales políticos de Estados Unidos ${ }^{[8]}$. El problema fue que Washington no reconoció que algunos de sus aliados en Oriente Medio tenían otros intereses, y por lo tanto conducían su política interna y externa en contravía a los intereses de la Casa Blanca. Por ejemplo, utilizaban métodos políticos inapropiados y alejados de la democracia para mantenerse en el poder o socavar la oposición política del momento, tal y como lo hicieron la policía secreta (Savak) del sha en Irán y el Servicio de Inteligencia Iraquí (Mukhabarat). Esto hizo pensar a los pobladores de la región que Washington estaba más preocupada en sus propios intereses que en los suyos, lo cual generó una imagen negativa del país que facilitó el ascenso de un fuerte sentimiento antiestadounidense, altamente contraproducente para los intereses de Washington, tal y como ocurrió luego de la caída del sha de Irán en $1979^{[9]}$.

Así, la credibilidad de Estados Unidos en la región se erosionó a raíz de las contradicciones e inconsistencias a la hora de promover y defender sus ideales de libre autodeterminación, democracia y libertad en Oriente Medio. Y si bien en algunos países lo consiguió, la sobreprotección a Israel y la consecuente pasividad ante el martirio del pueblo palestino anularon cualquier logro positivo por parte de Estados Unidos.

A partir de la administración de Harry Truman (1945-1953), Washington ha preservado una "relación especial” con Israel. No obstante, el lobby israelí ha generado la toma de decisiones que van en contravía de los intereses estadounidenses en Oriente Medio y que han sumergido al país en una situación muy complicada luego de los atentados del 9-11 y la posterior intervención en Irak en el 2003. En 1968 el antiguo embajador de Estados Unidos en Egipto John Badeau lo presagió: "En el contexto de la política exterior americana, Israel [...] debe ser visto más como problema, que como un interés" (Badeau, 1968, citado en T. Ismael, 1986, p. 138).

El tema israelí ha sido y será neurálgico en la política exterior de Estados Unidos hacia Oriente Medio. El 6 de marzo de 1991, el presidente George H. Bush manifestó su interés en la necesidad de un Israel seguro, pero también manifestó que su país estaba interesado en un compromiso de territorio por paz, lo cual no fue bien visto por sectores radicales judíos, los cuales ya estaban resentidos por no haber recibido autorización para responder a los ataques de Hussein meses atrás. Ello develó que Israel ya no tenía autonomía para tomar 
decisiones en el tablero geopolítico de la región al finalizar la Guerra Fría, sin dudas, uno de los cambios sistémicos más importantes de la región.

\section{Del fin de la Guerra Fría la guerra del Golfo (1990)}

A finales de la década de 1980, se presentaron hechos históricos fundamentales para el sistema internacional. En 1989 cayó el Muro de Berlín y se unificó Alemania, y en 1990 colapsó la Unión Soviética, lo cual generó cambios en el equilibrio de poder y en la estructura global. Otros analistas hablaron del fin de la historia (Fukuyama, 1989), y mientras algunos señalaban la llegada de un momento "unipolar" (Krauthammer, 1990) [10] , otros como el presidente George H. Bush manifestaron el surgimiento de "nuevo orden mundial" [11] . Este nuevo panorama dejó a Estados Unidos como un hegemón por defecto de un sistema internacional que empezó a reconfigurarse en la arena política, económica y militar. Asimismo, se hizo evidente el papel de otros actores poderosos tradicionales como la Unión Europea y Japón; de potencias emergentes o BRICS (Brasil, Rusia, China, India y Sudáfrica). Asimismo, Rusia, a pesar de ya no contar con los recursos materiales y estratégicos de sus repúblicas vecinas, continuó siendo importante en el campo militar. Esto explica por qué el sistema internacional a partir de ese momento se complejizó, y la agenda de temas se amplió, lo que generó una multipolaridad más compleja que la unipolaridad pensada en principio, Joseph Nye (1991) lo explica así:

EE. UU. posee un portafolio diversificado de recursos mayor al de cualquier otro país, pero el nuevo orden mundial no será una era de hegemonía americana. El orden mundial de la posguerra fría es sui generis [...] el poder ha llegado a ser multidimensional, las estructuras más complejas y los estados más permeables. Ésta complejidad quiere decir que el orden mundial reposa en algo más que en el equilibrio de poder tradicional. (p. 88)

¿Qué sucedió con los intereses de Estados Unidos en Oriente Medio en este nuevo escenario? Para Herrmann y Halliday la importancia de Israel y el petróleo ${ }^{[12] ~ p e r m a n e c i o ́ ~ v i g e n t e ~ e n ~ l a ~ a g e n d a ~ d e ~}$ Washington hacia la región. No obstante, el fin de la Guerra Fría generó otros temas que se debieron tratar a través de una estrategia política de disuasión más efectiva, ya que la Operación Tormenta del Desierto (1991), si bien redujo una posible amenaza militar por parte de Irak, no eliminó las tendencias políticas antiestadounidenses que empezaban a consolidarse en la región. De la misma manera, para el autor en mención es evidente que la política exterior estadounidense falló en prevenir la guerra del Golfo: se centró en disuadir a Irán, y no identificó los problemas importantes de la política intra-árabe que estaban polarizando a la región. Esto no permitió el desarrollo de una estrategia política adecuada de seguridad regional y obligó a utilizar la superioridad militar, con consecuencias negativas para los intereses de Estados Unidos. Lo anterior, es reflejo de la política de "contención dual" llevada a cabo por la administración Clinton, que buscaba dejar de balancear a Irán en contra de Irak (Balmaceda, Brieger y Sfrégola, 2000, p. 6).

El principal desafío para Washington ya no era la amenaza militar de algunos actores regionales, puesto que la retaliación estadounidense sería fatal para ellos: el principal problema ahora lo constituía la percepción -doméstica - en las sociedades árabes que veían a Estados Unidos como un poder imperial con nexos con algunas de sus élites. Amplios sectores del nacionalismo árabe y del populismo islámico empezaron a desafiar a dichas élites y atacar a ciudadanos estadounidenses vulnerables. Herrmann (1991) señala al respecto:

El dilema estratégico para EE. UU. es más político que militar. Puede proteger su influencia por la fuerza y coerción, tal y como lo hizo Moscú durante años en Europa Oriental, pero: ¿Cómo puede construir relaciones positivas con los países de Oriente Medio, que van a superar cambios internos con una demanda creciente del empoderamiento de público? (p. 43)

El fin de la Guerra Fría transformó el contexto de la región. Según Halliday, durante el lapso de 1980 al 2000 no existió interdependencia en la zona, su lógica se basaba en modelos regionales de conflictos y alianzas que prevalecieron sobre la rivalidad de los grandes poderes. Además, tenía cierta autonomía sobre las tendencias globales, algo que cambiaría luego de la intervención militar en Irak en el 2003. 


\section{Hussein y la construcción de aliados y enemigos}

La actitud de Hussein a inicios de la década de 1990 afectó el orden del sistema que Estados Unidos había configurado, de alguna manera, en la región. Hizo que Washington quebrantara principios como el uso prohibido de la amenaza y la fuerza, la legitimidad de la ONU como árbitro de las disputas territoriales internacionales y la inviolabilidad del sistema de Estados de la posguerra. Asimismo, un Hussein con posibles armas de destrucción masiva (WMD, por sus siglas en inglés) hizo que la opinión pública estadounidense considerara una acción armada contra el dictador como algo necesario. Pero el análisis no era tan simple para el mundo árabe, ya que no creían que se tratara de una motivación de Washington por defender principios universales.

En aquel entonces era persistente en la memoria colectiva de la región, la agresión de Irak a Irán (1980-1988) auspiciada por Estados Unidos, que le apostó a un equilibrio de poder, a través de un cruento conflicto que debilitó a ambos Estados y aisló a Siria en su confrontación con Israel. En el mismo orden, las diferentes administraciones de la Casa Blanca nunca exigieron un cumplimiento rápido y efectivo de las Resoluciones de la ONU sobre el Conflicto Árabe-Israelí (UN-242, UN-338) ni tampoco del cese al fuego del conflicto Irán-Irak (UN-598), pero en cambio Washington sí exigió el cumplimiento de doce resoluciones favorables a Kuwait. Debido a esto, algunos líderes regionales consideraron apresurado recurrir a la guerra, luego de sólo cinco meses de sanciones, y cuando vieron que la principal estrategia bélica estadounidense consistía en bombardeos aéreos, no pensaron que se estaba protegiendo a Kuwait, sino todo lo contrario, que se estaba destruyendo la capacidad militar de un país árabe fuerte. Además, por primera vez en la historia moderna, los árabes se aliaron con Occidente para luchar contra un Estado hermano, el evento sistémico más dramático de la posguerra fría en la región ${ }^{[13]}$.

La falta de apoyo a los levantamientos kurdos y chiitas en el norte y en el sur del país, respectivamente, confirmó los rumores en la región de que Estados Unidos estaba defendiendo sus propios intereses económicos, a las monarquías exportadoras de petróleo, y a Israel, a través de la fuerza militar. Para el mundo árabe, fue evidente que Estados Unidos no tenía ninguna intención de generar un cambio político en la zona, argumento que luego utilizarían grupos fundamentalistas de la región que resaltaban la imagen de Estados Unidos como un imperio enemigo, lo cual hizo que el dilema de seguridad fuera una constante para Washington en la zona.

A principios de la década de 1990, Saddam Hussein ya no era el mismo dictador de la Guerra Fría, y Estados Unidos se dio cuenta tarde de ello. Además, las fallas del Plan Baker, debido a la presión israelí debilitaron la imagen de Hosni Mubarak en Egipto y polarizaron aún más el ambiente político en Oriente Medio ${ }^{[14]}$. Y fue en ese momento cuando surgió un Hussein con una visión más independiente, y con un discurso agresivo que escapaba a la lógica bipolar hegemónica impuesta en la región hasta el momento. Para el dictador, el mundo árabe tenía que valerse por sí mismo y dejar de ser dependiente de las decisiones políticas y económicas extranjeras. Según Herrmann (1991):

Saddam presentó una visión de un gran poder árabe que emergía luego del ocaso de la hegemonía bipolar de Estados Unidos. y la URSS. El Mundo Árabe sería independiente y autosuficiente, no suplicaría favores a Occidente y pediría un trato justo desde una posición fuerte. Fue un mensaje emocionante para millones de árabes. Ellos vieron a Saddam como su Bismarck. Saddam podría haber eclipsado a Asad, [...] y podría haber obligado a Egipto y Arabia Saudita a seguirlo. (p. 43)

Hussein tenía la doble capacidad de proyectar poder dentro y fuera de su país. En el primer caso, se podía valer de su fuerza militar, y en el segundo, apelaba al sentimiento antiisraelí y antiestadounidense de acuerdo con el momento y la necesidad, complementando esto con el uso apropiado de símbolos nacionalistas árabes [15] . Varios hechos corroboran el cambio en la actuación de Hussein: ciertos oficiales que visitaron Irak en 1990 identificaron un comportamiento agresivo y hostil. En discursos a su pueblo, el dictador describió a Estados Unidos como el enemigo de la nación árabe, y fue demasiado tarde cuando Washington ordenó 
realizar maniobras aéreas desde los Emiratos Árabes Unidos en julio de 1990. Dichas acciones no disuadieron al dictador, quien pensaba que Estados Unidos no tenía el suficiente interés para responder militarmente a la toma de Kuwait. En ese sentido, Hermann (1991) señala: "La decisión de Saddam de no tomar el territorio saudí, y su posterior decisión de liberar rehenes occidentales indican que pudo haber sentido que Kuwait podría ser absorbida sin guerra” (p. 52).

A pesar de la osadía de Hussein, varios emisarios procedentes de la Unión Soviética y del propio mundo árabe intentaron convencerlo para que detuviera su pretensión sobre Kuwait a tiempo, pero todos fracasaron. Uno de los más importantes fue el enviado de Moscú Yevgeni Primakov, quien llevó propuestas a Hussein en octubre de 1990 y febrero de $1991^{[16]}$. De la misma manera, enviados de Yemen y Jordania fracasaron, incluso el presidente argelino Chadli Bendjedid realizó un viaje por la región en diciembre de 1990 y presentó una propuesta a Hussein, quien la rechazó, y además recalcó que no había resultados positivos frente al conflicto árabe-israelí.

El 12 de agosto, diez días después de la invasión, Hussein hizo una propuesta utópica: sus tropas saldrían de Kuwait, solo si al mismo tiempo Israel desalojaba los territorios ocupados, así como también el ejército estadounidense debería salir de Arabia Saudita, además del levantamiento total de las sanciones contra Irak, peticiones a nivel sistémico imposibles de cumplirse. Pero esto no era todo, el 15 de febrero de 1991 (el 15 de enero debería haberse retirado de Kuwait, según el ultimátum de la ONU) y ya bajo bombardeos estratégicos, el Comando del Consejo Revolucionario Iraquí manifestó que se retiraría bajo las siguientes condiciones: (i) cese al fuego total; (ii) cancelación de las resoluciones del Consejo de Seguridad de la ONU relativas al conflicto; (iii) retiro de las fuerzas estadounidenses de todo Oriente Medio; (iv) retiro definitivo de Israel de Palestina y de los territorios árabes ocupados en el Golán y el sur del Líbano; (v) el no regreso de la familia AlSabah a Kuwait; (vi) los países que atacaron a Irak (coalición) deberían pagar los gastos de la reconstrucción del país; (vii) la deuda iraquí debería ser cancelada; y (viii) la región del golfo Pérsico debería declararse libre de cualquier presencia militar extranjera ${ }^{[17]}$.

Luego de esto, la historia indica que Irak fue castigado con duras sanciones (Cordesman y Hashim, 1997; T. Ismael y J. Ismael, 2005; J. Mueller y K. Mueller, 1999), que debilitaron a Hussein, y que por defecto facilitarían el ascenso de un Irán nuclear. En aquel momento no se contaba con los atentados del 9-11 y las terribles repercusiones de la intervención ilegal ordenada por George W. Bush en el 2003, quien acusó falsamente a Hussein de poseer un arsenal nuclear y tener vínculos con $\mathrm{Al}$ Qaeda, falsedades que desencadenaron un conflicto que cambió la historia de Oriente Medio para siempre.

\section{Conclusiones}

Hemos confirmado la importancia del papel de Estados Unidos en la construcción histórica de Oriente Medio. Con el realismo neoclásico identificamos intereses que han sido contantes, tales como los recursos energéticos, el apoyo a Israel y a las élites prooccidentales (factores sistémicos). No obstante, la promoción de valores y democracia se vio empañada por el apoyo a regímenes autoritarios (factores domésticos) y la promoción de conflictos con los que buscó alejar a la Unión Soviética de la zona (Bosemberg, 2003). Algunos factores —sistémicos y domésticos— han variado, por ejemplo: golpes de Estado (Irán, 1953) (Irak, 1979), revolución iraní (1978) y la desaparición de la Unión Soviética (1991), entre otros.

El doloroso pasado colonial nunca se olvidó en la región. La larga ocupación europea dejó graves consecuencias en el imaginario colectivo de la zona. En el caso iraquí, persistían las secuelas de la ocupación británica de Basora en 1941 y las masacres que dejó el uso de armas aéreas y artillería que se utilizó contra la población luego de la Segunda Guerra Mundial, de lo que quedó un tristemente célebre manual de bombardeo (Khalidi, 2004, p. 53). 
Durante el sistema bipolar (1945-1991) Irak nunca atacó a Estados Unidos, pero luego del fin de la Guerra Fría los cálculos y la percepción de Hussein fallaron. El dictador no supo interpretar el contexto ni el escenario que se presentaba en Oriente Medio en aquel momento. Su gobierno funcionaba en medio de una lógica perversa, en la cual solo se decía lo que el mandatario quería oír, por miedo a la tortura, el destierro o la propia muerte, lo cual creó un ambiente de percepciones erróneas en su inner circle de asesores - factores domésticos

— ${ }^{[18]}$. Asimismo, el régimen iraquí estaba mal informado sobre la capacidad real de algunas de sus armas de origen soviético, las cuales eran deficientes frente al poder aéreo israelí, su más fuerte adversario regional, y más aún, frente a la táctica y poder de fuego de Estados Unidos y sus aliados ${ }^{[19]}$.

De la misma manera, las percepciones geoestratégicas de Hussein eran erróneas: Herrmann (1991) las describe así: (i) Estados Unidos se podría oponer a la hegemonía de Irak en la región, pero no al punto de usar la fuerza militar; (ii) el nivel de animadversión contra Estados Unidos en el mundo árabe era tan alto que ningún gobierno permitiría establecer tropas extranjeras en su suelo; y (iii) si algún gobierno árabe pedía protección a Estados Unidos, perdería su legitimidad y sería posteriormente derrocado (p. 54). Ninguna de las tres percepciones fue correcta. Más adelante se comprobará que el ataque estadounidense fue "parcial", ya que no sacó a Hussein del poder, y las posteriores sanciones económicas impuestas generaron consecuencias dramáticas en contra de la población ${ }^{[20]}$, pero no en la estructura del régimen que se sostenía en medio de corrupción, opresión y violaciones constantes a los derechos humanos, y que se valía de la temerosa Mukhabarat, aparato de inteligencia y seguridad interna del régimen para mantener el statu quo.

Finalmente, la estrategia de disuasión estadounidense falló y no logró pacificar la región. La manera en que Washington intervino, evidenció que no estaba en busca de proteger la libertad y seguridad de los ciudadanos y que solo trató de conservar socios comerciales. El 6 de marzo de 1991, en la Declaración de Damasco, el presidente egipcio Hosni Mubarak propuso limitar la venta de WMD a la región, algo que Israel rechazó de facto y que develó el eterno dilema de seguridad en una región en donde los árabes no querían seguir legitimando la inmensa ayuda militar a Israel y las desproporcionadas restricciones a ellos. Esta tendencia continuaría en los próximos años, durante las administraciones de G. H. Bush, Bill Clinton y G. W. Bush, lo que haría inevitable el advenimiento de nuevas tensiones, sanciones perversas e ineficaces y una nueva e innecesaria guerra en el 2003. En palabras de Khalidi, una "peligrosa aventura" que años después el propio presidente Barack Obama no logró cerrar adecuadamente.

\section{Referencias}

Ali, M., Blacker, J., y Jones, G. (2003). Annual mortality rates and excess deaths of children under five in Iraq, 1991-98. Population Studies, 57(2), 217-226. DOI: https://doi.org/10.1080/0032472032000097119

Aranda, G., y José, M. (2005). Hegemonia norteamericana en Medio Oriente. Algunas premisas. Revista de Estudios Árabes, (1), 9-30. Recuperado de https://www.repositorio.uchile.cl/bitstream/handle/2250/123155/Hegemo nia-Norteamericana-en-Medio-Oriente.pdf?sequence=1\&isAllowed $=y$

Badeau, J. (1968). The American approach to the Arab world. Nueva York: Harper and Row.

Baghdad Domestic Service. (1990, 12 de agosto). Saddam's Hussein initiative.

Balmaceda, L., Brieger, P., y Sfrégola, C. (2000). Estados Unidos y la contención dual. Ponencia presentada en las III Jornadas de Medio Oriente. IRI (UNLP), La Plata, Argentina. Recuperado de https://www.sedici.unlp.edu.ar /handle/10915/41170

Barbé, E. (2005). Orden internacional: ¿Uno o varios? Neoimperialismo, caos y posmodernidad. En Cursos de derecho internacional y relaciones internacionales de Vitoria-Gasteiz 2004 (pp. 155-190). Bilbao: Servicio Editorial de la Universidad del País Vasco.

Bichler, S., y Nitzan, J. (2004). Dominant capital and the new wars. Journal of World-Systems Research, 10(2), 255-327. Recuperado de https://www.jwsr.pitt.edu/ojs/index.php/jwsr/article/view/304/316 
Bosemberg, L. E. (2003). Estados Unidos y el Medio Oriente: moderación, rivalidad y hegemonía. Historia Crítica, (26), 9-23. Recuperado de https://www.revistas.uniandes.edu.co/doi/pdf/10.7440/histcrit26.2003.01

Brawley, M. R. (2009). Neoclassical realism and strategic calculations. En S. E. Lobell, N. M. Ripsman y J. W. Taliaferro (eds.), Neoclassical realism, the State, and foreign policy (pp. 75-98). Cambridge, Reino Unido: Cambridge University Press.

Chomsky, N. (2004). Los dilemas de la dominación. En A. Borón (ed.), Nueva hegemonía mundial (pp. 3-14). Buenos Aires: Clacso.

Claire, R. W. (2004). Raid on the sun: inside Israel's secret campaign that denied Saddam the bomb. Nueva York: Broadway Books.

Cordesman, A. H., y Hashim, A. (1997). Iraq: sanctions and beyond. Boulder, Colorado: Westview Press.

Drezner, D. W. (2007). The new new world order. Foreign Affairs, 86(2), 34-46. Recuperado de https://www.jstor.o rg/stable/20032282?seq=1\#page_scan_tab_contents

Dueck, C. (2004). Ideas and alternatives in American grand strategy, 2000-2004. Review of International Studies, 30(04), 511-535. DOI: https://doi.org/10.1017/S0260210504006205

Dueck, C. (2009). Neoclassical realism and the national interest: presidents, domestic politics, and major military interventions. En S. E. Lobell, N. M. Ripsman y J. W. Taliaferro (eds.), Neoclassical realism, the State, and foreign policy (pp. 139-169). Cambridge, Reino Unido: Cambridge University Press.

Dunn, D. H. (2003). Myths, motivations and 'misunderestimations': the Bush Administration and Iraq. International Affairs, 79(2), 279-297. DOI: https://doi.org/10.1111/1468-2346.00308

Fawcett, L. (2005). International relations of the Middle East. Oxford: Oxford University Press.

Fordham, B. O. (2009). The limits of neoclassical realism: additive and interactive approaches to explaining foreign policy preferences. En S. E. Lobell, N. M. Ripsman y J. W. Taliaferro (eds.), Neoclassical realism, the State, and foreign policy (pp. 251-279). Cambridge, Reino Unidos: Cambridge University Press.

Fukuyama, F. (1989). The end of history? The National Interest, 16(4), 3-18. Recuperado de https://www.jstor.org/ stable/24027184?seq=1\#page_scan_tab_contents

Gaddis, J. L. (1982). Strategies of containment: a critical appraisal of American national security policy during the Cold War. New Jersey: Oxford University Press.

Gaddis, J. L. (2007). The Cold War: a new history. Nueva York: Penguin Group.

Halliday, F. (2005). The Middle East in international relations. Nueva York: Cambridge University Press.

Herring, E., y Rangwala, G. (2005). Iraq, imperialism and global governance. Third World Quarterly, 26, 667-683. DOI: https://doi.org/10.1080/01436590500127909

Herrmann, R. K. (1991). The Middle East and the new world order: rethinking U.S. political strategy after the Gulf War. International Security, 16(2), 42-75. Recuperado de https://www.jstor.org/stable/2539060

Heydemann, S. (2000). War, institutions, and social change in the Middle East. Los Ángeles: University of California Press.

Hinnebusch, R. A., y Ehteshami, A. (2002). The foreign policies of Middle East States. Boulder, Colorado: Lynne Rienner Publishers.

Howard, H. (1974). The United States and the Middle East. En T. Ismael (ed.), The Middle East in world politics (pp. 181-194). Nueva York: Syracuse University Press.

Ismael, T. (1986). International relations of the contemporary Middle East. A study in world politics. Nueva York: Syracuse University Press.

Ismael, T. e Ismael, J. (2005). Whither Iraq? Beyond Saddam, sanctions and occupation. Third World Quarterly, 26, 609-629. DOI: https://doi.org/10.1080/01436590500128303

Khalidi, R. (2004). La reafirmación del Imperio: Estados Unidos y la aventura occidental en Oriente Próximo. Madrid: Catarata.

Klarevas, L. J., Gelpi, C., y Reifler, J. (2006). Casualties, polls, and the Iraq war. International Security, 31(2), 186-198. DOI: https://doi.org/doi:10.1162/isec.2006.31.2.186 
Krauthammer, C. (1990). The unipolar moment. Foreign Affairs, 70(1), 23-33. Recuperado de https://www.jstor.or $\mathrm{g} /$ stable/20044692

Krauthammer, C. (2002). The unipolar moment revisited. The National Interest, (70), 5-18. Recuperado de https:// www.nationalinterest.org/article/the-unipolar-moment-revisited-391

Kupchan, C. A. (1987). The Persian Gulf and the West: the dilemmas of security. Boston: Allen and Unwin.

Layne, C. (2009). America's Middle East grand strategy after Iraq: the moment for offshore balancing has arrived. Review of International Studies, 35(01), 5-25. DOI: https://doi.org/doi:10.1017/S0260210509008304

Le Billon, P. (2005). Corruption, reconstruction and oil governance in Iraq. Third World Quarterly, 26, 685-703.

Lobell, S. E. (2009). Threat assessment, the state, and foreign policy: a neoclassical realist model. En S. E. Lobell, N. M. Ripsman y J. W. Taliaferro (eds.), Neoclassical realism, the State, And foreign policy (pp. 42-74). Cambridge, Reino Unido: Cambridge University Press.

Lobell, S. E., Ripsman, N. M., y Taliaferro, J. W. (2009). Neoclassical realism, the State, and foreign policy. Cambridge, Reino Unido: Cambridge University Press.

Mearsheimer, J., y Walt, S. (2007a). El lobby d'Israel. Badalona: Ara

Mearsheimer, J., y Walt, S. (2007b). The Israel lobby and U.S. foreign policy. Nueva York: Farrah, Strauss, and Giroux.

Morgenthau, H. (1948). Politics among nations: the struggle for power and peace. Nueva York: Alfred Knopf.

Mueller, J., y Mueller, K. (1999). Sanctions of mass destruction. Foreign Affairs, 78(3), 43-53. Recuperado de https: //www.jstor.org/stable/i20049272

Nitzan, J., y Bichler, S. (2002). The weapondollar-petrodollar coalition. Sterling, Virginia: Pluto Press.

Nitzan, J., y Bichler, S. (2006). Cheap wars. The Economy of the Occupation. A Socioeconomic Bulletin, 10, 1-32. Recuperado de https://www.bnarchives.net

Nye, J. S. (1991). What new world order? Foreign Affairs, 71(2), 83-96. Recuperado de https://www.foreignaffairs.c om/articles/1992-03-01/what-new-world-order

Raas, W., y Long, A. (2007). Osirak redux? Assessing Israeli capabilities to destroy Iranian nuclear facilities. International Security, 31(4), 7-33. DOI: https://doi.org/10.1162/isec.2007.31.4.7

Ripsman, N. M. (2009). Neoclassical realism and domestic interest groups. En S. E. Lobell, N. M. Ripsman y J. W. Taliaferro (eds.), Neoclassical realism, the State, and foreign policy (pp. 170-193). Cambridge, Reino Unidos: Cambridge University Press.

Ripsman, N. M., y Levy, J. S. (2008). Wishful thinking or buying time? The logic of British appeasement in the 1930s. International Security, 33(2), 148-181. DOI: https://doi.org/doi:10.1162/isec.2008.33.2.148

Schweller, R. L. (1998). Deadly imbalances: tripolarity and Hitler's strategy of world conquest. Nueva York: Columbia University Press.

Schweller, R. L. (2004). Unanswered threats: a neoclassical realist theory of underbalancing. International Security, 29(2), 159-201. Recuperado de https://www.jstor.org/stable/4137589

Schweller, R. L. (2009). Neoclassical realism and state mobilization: expansionist ideology in the age of mass politics. En S. E. Lobell, N. M. Ripsman y J. W. Taliaferro (eds.), Neoclassical realism, the State, and foreign policy (pp. 227-250). Cambridge, Reino Unido: Cambridge University Press.

Slaughter, A. M. (1997). The real new world order. Foreign Affairs, 76(5), 183-197. Recuperado de https://www.for eignaffairs.com/articles/1997-09-01/real-new-world-order

Sterling-Folker, J. (2009). Neoclassical realism and identity: peril despite profit across the Taiwan Strait. En S. E. Lobell, N. M. Ripsman y J. W. Taliaferro (eds.), Neoclassical realism, the State, and foreign policy (pp. 99-138). Cambridge, Reino Unido: Cambridge University Press.

Vereté, M. (1970). The Balfour declaration and its makers. Middle Eastern Studies, 6(1), 48-76. DOI: https://doi.org /10.1080/00263207008700138

Walt, S. (1987). The origins of alliances. Nueva York: Cornell U. P.

Waltz, K. N. (1979). Theory of international politics. Reading, MA: Addison-Wesley. 
Woods, K., Lacey, J., y Murray, W. (2006). El engaño de Hussein visto desde adentro. Foreign Affairs en Español, 6(3), 19-45. Recuperado de https://revistafal.com/numeros-anteriores/fal-06-3/

"X" Kennan, G. (1947). The sources of Soviet conduct. Foreign Affairs, 25, 566-582. Recuperado de https://www.fo reignaffairs.com/articles/russian-federation/1947-07-01/sources-soviet-conduct

\section{Notas}

[1] En aquel momento aún eran colonia de Inglaterra. Con el fin de la guerra de los Siete Años (1756-1763), algunos comerciantes a favor de la independencia mantuvieron relaciones comerciales que antes hacían bajo el título de colonia; su objetivo era suplir el abastecimiento que ya no llegaba desde Inglaterra.

[2] Algunas élites políticas del mundo árabe copiaron los valores liberales occidentales, avances científicos, técnicos, educativos y culturales; asimismo, adoptaron la organización militar, judicial y de gobierno. No obstante, dichas élites se vieron traicionadas por las democracias europeas (Francia y Gran Bretaña), las cuales estaban más preocupadas por expandir sus imperios que por difundir ideales democráticos y constitucionales, sin permitir la libre autodeterminación árabe (Khalidi, 2004, pp. 33-36, 41-59).

[3] Dichas comisiones en sus informes finales concluyeron que la población local se oponía al sionismo en la zona y a la creación de un Estado judío independiente (Mearsheimer y Walt, 2007a, 2007b ).

[4] Esta declaración también confirmaba la oposición generalizada en la región a la creación de un Estado judío. La carta enviada por el secretario de Estado de Relaciones Exteriores, Arthur James Balfour, a lord Rothschild, buscaba conseguir el apoyo de la comunidad judía al esfuerzo bélico en la Primera Guerra Mundial. Conocida como la Declaración de Balfour, se convirtió en una de las bases legales para crear un Estado judío en Palestina. La carta fue publicada en el Times de Londres una semana más tarde. El texto manifestaba: "Foreign Office, 2 de noviembre de 1917. Estimado Lord Rothschild: Tengo sumo placer en comunicarle en nombre del Gobierno de Su Majestad, la siguiente declaración de simpatía con las aspiraciones judías sionistas, declaración que ha sido sometida a la consideración del gabinete y aprobada por el mismo: el Gobierno de Su Majestad contempla con simpatía el establecimiento en Palestina de un hogar nacional para el pueblo judío, y empleará sus mejores esfuerzos para facilitar el cumplimiento de este objetivo, quedando claramente entendido que no se hará nada que pueda perjudicar los derechos civiles y religiosos de las comunidades nojudías existentes en Palestina, o los derechos y estatus político de que gozan los judíos en cualquier otro país. Le agradeceré que lleve esta declaración a conocimiento de la Federación Sionista” (Vereté, 1970).

[5] No se debe olvidar la expansión del imperio zarista sobre el Cáucaso y Turkestán durante el siglo XIX (T. Ismael, 1986, p. 136).

[6] Para Khalidi, la luna de miel entre el mundo árabe y Estados Unidos termina con el apoyo de Washington a Israel y la pobreza y opresión del pueblo Palestino (2004, p. 61).

[7] En aquel momento Europa occidental dependía directamente del petróleo de Oriente Medio.

[8] Un trabajo valioso y riguroso sobre la formación de alianzas en la región lo hace Stephen Walt (1987). El autor revisa las alianzas en la región durante el lapso 1955-1979 y encuentra que los Estados buscan aliarse contra los más fuertes en vez de unírseles (bandwagon), lo que denomina equilibrio de miedo, algo que le autor considera más acertado que el concepto tradicional de equilibrio de poder.

[9] El rechazo hacia Occidente se ha presentado en distintas épocas y lugares de la región, por citar algunos ejemplos: el movimiento wahhabi de la Península Arábiga (siglo XVIII), el movimiento mahdi en Sudán (siglo XIX) y los Hermanos Musulmanes en Egipto (1930) (Khalidi, 2004, p. 36). Luego de los atentados del 11-S en Nueva York, Al Qaeda se convirtió en el ícono del fundamentalismo y el rechazo a los "infieles". Actualmente, genera temor el terrorismo transnacional del autodenominado Estado Islámico (ISIL o ISIS, por sus siglas en inglés).

[10] El autor, años después, reconoció su visión limitada, ya que diversos actores emergentes estaban ejerciendo presión en la estructura del sistema internacional (Krauthammer, 2002).

[11] Barbé es contundente al aclarar los siguientes conceptos, muy utilizados en el campo de las RRII: "El término de Nuevo Orden Internacional, tras la Segunda Guerra Mundial, y el de Nuevo Orden Mundial, tras el fin de la Guerra Fría, han servido a los presidentes de EE. UU. para articular la política exterior de su país” (Barbé, 2005, p. 157). Asimismo, la autora, valiéndose de los postulados clásicos de Bull, expone: "Hay que precisar que Bull diferencia entre orden mundial, basado en las relaciones establecidas entre personas, y orden internacional, basado en un sistema de reglas y expectativas establecidas entre estados. Dichas reglas y expectativas conformarían el orden internacional” (Barbé, 2005, p. 160). Sobre la dificultad que presenta el estudio del "orden mundial”, resultan valiosos los trabajos de Slaughter (1997) y de Drezner (2007).

[12] Se debe tener en cuenta que tanto el petróleo como la seguridad de Israel motivaron la política de contención del comunismo en Oriente Medio, la protección de las vías de acceso a los recursos, y un notable desaliento hacia el cambio 
político en la región. La búsqueda de estos objetivos obligó a Washington a buscar y mantener aliados a través de una escalada militar y financiera en el transcurso de varios años, que fue acompañada por la fuerza y la intervención política directa. Asimismo, el conflicto árabe-israelí complicó las cosas y llevó a que algunos nacionalistas árabes buscaran apoyo en la Unión Soviética. A pesar de lo anterior, algunos dirigentes en Washington tenían la esperanza de lograr un consenso estratégico en el que se unieran árabes, israelíes, turcos y persas, en una causa común contra la Unión Soviética, lo cual lógicamente nunca se materializó, y ocasionó que la Casa Blanca terminara implementando una estrategia unilateral y radical de fuerza militar que complicaría mucho más las cosas en los siguientes años (Kupchan, 1987, citado en Herrmann, 1991, p. 44).

[13] Halliday enfatiza que se trató de una división intra-árabe más profunda que la "Guerra Fría Árabe de la década de 1960" o cuando se presentó la "apertura” de Egipto a Israel en 1977-1979. Asimismo, manifiesta que muchos saudíes vieron la invasión iraquí de Kuwait como parte de una "encerrona hachemita” (2005, pp. 143, 225).

[14] Para Khalidi, el logro de James Baker fue muy valioso: sentar en una misma mesa a todos los implicados en el conflicto árabe-israelí: "[...] un logro sin precedentes desde que la Declaración Balfour en 1917 creara un conflicto internacional sobre Palestina” (2004, p. 188) Asimismo, este autor explica las fallas de las posteriores conversaciones en Oslo, Madrid y Washington, debido a las fuertes presiones israelíes.

[15] A pesar de su historia como un árabe exitoso, Hussein nunca tuvo el nivel de popularidad de otros líderes árabes como Nasser. Nunca fue el héroe de populistas islámicos, a pesar de que empleara sus símbolos, es más, muchos fundamentalistas islámicos lo veían como culpable de haber masacrado a la elite islámica en el país y a su propio pueblo debido a su ambición. Su ego acabó con la Umma y sus actos perversos solo fueron superados por la brutal acción militar estadounidense (Herrmann, 1991, p. 64). De la misma manera, debido a que los árabes se identifican con múltiples comunidades, más allá de las fronteras establecidas al final del periodo colonial, los líderes de la región han competido usando símbolos transnacionales. Por ejemplo, Nasser desafió la legitimidad de los monarcas en Jordania, Arabia Saudita y Yemen, apelando a símbolos nacionalistas árabes y republicanos. El ayatollah Khomeini, por su parte, criticó a la familia real saudita por su dependencia y sumisión al imperialismo estadounidense.

[16] El 2 de agosto de 1990 Irak se anexionó el emirato kuwaití.

[17] Días después, el 21 de febrero de 1991, Hussein se dirigió a la nación y manifestó que las propuestas del día 15 tenían como propósito dividir las líneas enemigas, que la coalición estaba temerosa de la guerra y que Irak no retrocedería (Baghdad Domestic Service, 1990, citado en Herrmann, 1991, p. 53).

[18] El siguiente apartado es un buen ejemplo de la percepción equivocada (aunque no del todo) del aparato de gobierno de Hussein: "Ibrahim Ahmad Abd al-Sattar, Jefe del Estado Mayor del Ejército iraquí y de las Fuerzas Armadas, aseguró que Hussein creía que, aún si sus apoyos internacionales le fallaban, y EE. UU. lanzaba una invasión terrestre, Washington se doblegaría con rapidez ante la presión internacional para detener la guerra [...] Cuando tuvo lugar el asalto de la coalición, Hussein se aferró a la creencia de que los estadounidenses se contentarían con un resultado que no llegara al cambio de régimen. Según Sattar, 'Ningún dirigente iraquí creía que las fuerzas de la coalición llegarían a Bagdad'. La convicción de Hussein de que su régimen sobreviviría a la guerra fue la principal razón por la cual no ordenó a sus tropas prender fuego a los campos petroleros o abrir las presas para inundar el sur del país, acciones que vaticinaron muchos analistas si se presentaba una invasión" (Woods, Lacey y Murray, 2006).

[19] Años atrás, el 7 de junio de 1981, Israel realizó uno de los ataques anticipatorios más exitosos de la historia moderna. La Fuerza Aérea Israelí (IAF) (Israelí Air Force, por sus siglas en inglés) realizó una misión con aviones F-15 y F-16 para destruir el reactor nuclear iraquí en Osirak, con una táctica que después se hizo popular en conflictos posteriores: "golpe de precisión". Tanto pilotos como aviones regresaron a salvo, y pese al posterior debate político, la maniobra se puede calificar como un éxito (Raas y Long, 2007, p. 8). El riesgo de la maniobra era alto, por lo cual el gobierno del primer ministro Menachem Begin estaba dividido sobre esta, luego de su elección en 1977. No así la Agencia de Inteligencia Israelí (Mossad), que llevó a cabo maniobras secretas para ganar tiempo: intentó sabotear partes del reactor antes de que los fabricantes franceses lo instalaran en Irak, y se intentó asesinar a expertos nucleares iraquíes. No obstante, no lograron detener el programa y en octubre de 1980 el propio Mossad informó al primer ministro Begin que el reactor entraría en funcionamiento aproximadamente en junio de 1981, lo cual generó un acalorado debate con un solo resultado: atacar. El siguiente relato de la operación así lo detalla: "Después de meses de cuidadosa preparación, un equipo de dieciséis aviones de ataque conformado por ocho F-15 y ocho F-16 despegó desde la base aérea de Etzion en el Sinaí. El perfil de vuelo fue de baja altitud, a través del Golfo de Aqaba en el sur de Jordania, y luego a través del norte de Arabia Saudita. Cada F-16 cargaba dos bombas Mk-84 de 2 mil libras con espoletas retardadas. Estas bombas eran 'tontas' (sic), pues no tenían guía distinta que aquella provista por el avión que las soltaba. Los F-16 sí tenían sistemas de focalización abordo, que harían que las bombas 'tontas' fuesen bastante exactas, pero tal exactitud requeriría que el avión se acercara al blanco. El equipo de ataque llegó cerca de Osirak sin ser detectado y a baja altitud. Los F-16 se formaron en puntos predeterminados para iniciar sus corridas de bombardeos, mientras los F-15 conformaron patrullas aéreas como barreras de combate para interceptar aviones iraquíes. A cuatro millas del blanco, los F-16 subieron a 5 mil pies para luego caer en picada en Osirak y soltar sus bombas. A pesar de algunos problemas de navegación y las defensas aéreas iraquíes, por lo menos ocho de 
las dieciséis bombas soltadas dieron en el domo de contención del reactor. El equipo de ataque se dio la vuelta y subió a mayor altitud, regresando casi por el mismo camino por el que había venido. Todos los dieciséis aviones regresaron exitosamente a Israel después de volver a cruzar Jordania. Los resultados del ataque fueron espectaculares. El reactor fue totalmente destruido, dejando la mayor parte del área circundante sin daño alguno" (Raas y Long, 2007, p. 11, basados en Claire, 2004).

[20] Un minucioso estudio de la tasa de mortalidad infantil y la muerte de niños antes de los cinco años en Irak durante el lapso (1991-1998) muestra cómo las cifras crecieron de forma desproporcionada, debido a las sanciones impuestas al país. De acuerdo con los cálculos hechos, el exceso de muertes infantiles podría estar entre 400.000 y 500.000. Para más información véase Ali, Blacker y Jones (2003, p. 217). En otro trabajo, los autores señalan que en 1998 la tasa de mortalidad infantil era del 3,7\% y luego de la guerra subió al 12\%. Igualmente, la falta de sistemas sanitario y eléctrico adecuados ocasionaron un incremento de 40.000 muertes anuales de niños y 50.000 de ancianos (J. Mueller y K. Mueller, 1999, p. 49). Lastimosamente, los autores no citan sus fuentes y por lo tanto carecen de credibilidad, aunque las cifras están en una media de acuerdo con otros trabajos que abordan el tema.

* Artículo de reflexión

\section{Licencia Creative Commons CC BY 4.0}

Cómo citar este artículo: Sánchez, F. (2018). Realismo neoclásico y la política exterior de Estados Unidos en Oriente Medio. Papel Político, 23(2). 1-13. https://doi.org/10.11144/Javeriana.papo23-2.rnpe 